\title{
Erratum to: The proteomic signature of insulin-resistant human skeletal muscle reveals increased glycolytic and decreased mitochondrial enzymes
}

\author{
J. Giebelstein • G. Poschmann • K. Højlund • \\ W. Schechinger • J. W. Dietrich $\cdot$ K. Levin • \\ H. Beck-Nielsen • K. Podwojski • K. Stühler • \\ H. E. Meyer • H. H. Klein
}

Published online: 29 April 2012

(C) Springer-Verlag 2012

\section{Erratum to: Diabetologia}

DOI 10.1007/s00125-012-2456-x

Unfortunately, "negatively" and "positively" were inadvertently reversed in the legend to Fig. 6 . The third sentence of the legend should read: A complete dark red or dark blue label indicates proteins where combined spot volumes (combination of all spots where the respective protein was identified) were significantly positively (red) or negatively (blue) correlated with GDR $(p<0.05)$.

The online version of the original article can be found at http://dx.doi.org/ 10.1007/s00125-012-2456-x.

J. Giebelstein $\cdot$ W. Schechinger $\cdot$ J. W. Dietrich $\cdot$ H. H. Klein $(\square)$

Medizinische Klinik I, Berufsgenossenschaftliches,

Universitätsklinikum Bergmannsheil,

Klinikum der Ruhr Universität Bochum,

Bürkle-de-la-Camp-Platz 1,

44789 Bochum, Germany

e-mail: harald.klein@rub.de

G. Poschmann • K. Podwojski $\cdot$ K. Stühler · H. E. Meyer Medizinisches Proteom-Center, Ruhr Universität Bochum,

Bochum, Germany

K. Højlund $\cdot$ K. Levin $\cdot$ H. Beck-Nielsen

Diabetes Research Center, Department of Endocrinology,

Odense University Hospital,

Odense, Denmark
W. Schechinger

Bioavid Diagnostics,

Dieburg, Germany

K. Podwojski

Department of Statistical Methods in Genetics and Chemometrics,

Technical University Dortmund,

Dortmund, Germany

K. Stühler

Molecular Proteomics Laboratory,

Heinrich Heine Universität Düsseldorf,

Düsseldorf, Germany 